Jurnal Pengajian Melayu - JOMAS, Jilid 31, 2020: 89-111

\title{
CITRA DAKWAH DALAM LIRIK PUISI ENDOI
}

\author{
(FEATURES OF 'DAKWAH'IN 'ENDOI’LULLABIES)
}

\author{
Noor Sarah Abu Kassim \\ qaisara_syirazie@yahoo.com \\ Norazimah Zakaria \\ norazimah@fbk.upsi.edu.my \\ Universiti Pendidikan Sultan Idris \\ Tanjong Malim, Perak \\ Malaysia
}

Received: 9 September 2020; Accepted: 9 November 2020

\begin{abstract}
The word 'endoi' or 'buai' in the Malay language describes the act of swinging a cradle gently whilst singing lullabies. However, 'endoi' may also refer to the verbal ritual conducted by a Malay family to welcome the birth of a newborn. 'Endoi' is a Malay art form believed to contain features of 'dakwah' propagating Islamic teachings. This particular form of traditional Malay poetry has lyrics that are suitable for educating the young and spreading 'dakwah' within the community. Therefore, this study is defined by two objectives - identifying 'endoi'lyrics that contain the features of 'dakwah' and discussing their purpose as a 'dakwah' medium for the Malays. To achieve these objectives, the study employed the 'Dakwah Bil Lisan'methodology based on the 'dakwah'method conceptualised by famed religious figure Yusuf Al-Qardhawi. 'Dakwah Bil Lisan' is a unique technique or method in which the features 'dakwah' can be identified through the characteristics of the speaker at the time of its occurrence. Results showed that 'dakwah' is indeed present within 'endoi'lyrics based on the three components of Islam: faith (akidah), jurisprudence (syariah) and morals (akhlak). The lyrics were also found to be in line with the two core beliefs in Islam, which are the six pillars of faith or 'Rukun Iman' and the five tenets of Islam or 'Rukun Islam'. It can be concluded that the 'endoi' ritual can be practised amongst Malays as it contains features of 'akidah', 'syariah' and 'akhlak' crucial to the upbringing of a true Muslim.
\end{abstract}

Keywords: Traditional Poetry, Culture, Art, Endoi, Dakwah, Dakwah Methods. 


\begin{abstract}
Abstrak
Endoi bermaksud buai. Endoi juga merupakan tradisi lisan berbentuk perbuatan yang dijalankan khas bagi menyambut atau meraikan kelahiran bayi dalam sesebuah keluarga masyarakat Melayu. Endoi juga merupakan salah satu kesenian Melayu berbentuk hiburan yang mengandungi unsurunsur dakwah yang disampaikan kepada masyarakat. Dalam kumpulan puisi Melayu tradisional ini, endoi dilihat mempunyai lirik yang sangat sesuai dalam mendidik dan menyampaikan dakwah kepada masyarakat. Makalah ini mempunyai dua objektif utama, iaitu pertama mengenal pasti lirik endoi yang mengandungi unsur dakwah dan kedua menghuraikan peranan lirik endoi sebagai dakwah kepada masyarakat. Makalah ini menggunakan metodologi Dakwah Bil Lisan berdasarkan konsep dakwah Yusuf Al-Qardhawi. Dakwah Bil Lisan adalah suatu teknik atau metode dakwah yang banyak diwarnai oleh karakteristik bicara seseorang da'i atau mubaligh atau si penyampai pada waktu aktiviti dakwah itu dijalankan. Dapatan kajian ini mendapati dakwah yang terkandung dalam lirik puisi endoi ini bertepatan dengan kandungan dakwah berdasarkan tiga perspektif, iaitu akidah, syariah dan akhlak serta bertepatan dengan dua paksi kepercayaan yang wajib diketahui umat Islam, iaitu berlandaskan kepada Rukun Iman dan Rukun Islam. Implikasi kajian menunjukkan puisi endoi boleh dijadikan amalan dalam kalangan orang Melayu kerana puisi tersebut mengandungi epistemologi akidah, syariah dah akhlak Islamiah yang penting dalam pembentukan peribadi muslim yang sejati.
\end{abstract}

Kata Kunci: Puisi Tradisional, Budaya, Endoi, Dakwah, Metode Dakwah.

\title{
Pengenalan
}

Puisi tradisional merupakan satu bentuk kesusasteraan Melayu tradisional yang terdiri daripada pelbagai genre atau bentuk. Puisi tradisional ini meliputi pantun, teromba, peribahasa, teka-teki, mantera dan prosa berirama, syair dan sebagainya. Melalui puisi tradisional inilah juga segala panduan dan peraturan hidup diperturunkan daripada satu generasi kepada generasi yang lain. Keadaan ini menjadikan kedudukan puisi tradisional amat akrab dalam kehidupan masyarakat Melayu. Maka tidak hairanlah apabila mereka dapat menghasilkan begitu banyak puisi-puisi tradisional yang berkualiti untuk memudahkan kehidupan mereka. Puisi tradisional dalam pelbagai genre yang diwarisi oleh masyarakat Melayu hari ini tidak terhitung banyaknya. Warisan ini merupakan pusaka bangsa Melayu yang mengandungi nilai peradaban yang sangat tinggi, unik dan sangat luar biasa. Keanekaragaman genre dan bentuknya pula memberi gambaran bahasa, masyarakat Melayu zaman silam hidup dengan latar kehidupan yang sangat harmonis, rukun dan beretika (Abdul Halim Ali, 2006, p. 1).

Jelaslah di sini, walaupun dunia semakin maju, namun sesebuah bangsa masih memerlukan adat resam yang dibawa sejak zaman dahulu bagi mengimbangi kehidupan mereka. Banyak unsur nasihat dan teladan yang boleh diikuti melalui adat dalam masyarakat Melayu. Hal ini turut disokong oleh Mohd Rosli Saludin (2007, p. 6): 
Orang tua-tua ada mengatakan bahawa melalui puisi Melayu tradisional banyak makna yang tersimpan atau dikatakan di dalam pantun banyak makna yang terhimpun, di dalam pepatah banyaklah faedah, didalam bidal bantaklah bekal, di dalam ibarat banyaklah isyarat,di dalam perumpamaan banyaklah pedoman, di dalam gurindam banyaklah rahsia terpendam, di dalam teromba banyak aturan dinyata dan seterusnya.

Puisi tradisional memainkan peranan yang sangat penting dalam kehidupan masyarakat Melayu. Antara fungsi yang dapat dilihat antaranya ialah:

i. Sebagai alat untuk menyampaikan nasihat dan pengajaran secara tidak formal yang selalunya berunsurkan bibit-bibit psikologi yang agak lembut.

ii. Selain itu juga ia berfungsi sebagai alat untuk merakamkan peristiwa-peristiwa yang terjadi pada zaman lampau. Meskipun gambarannya tidak begitu lengkap, paling sedikitpun terdapat nama-nama tempat dan tokoh-tokoh yang disebutkan dapat dijadikan sebagai petunjuk di mana peristiwa itu terjadi.

iii. Seterusnya puisi Melayu juga berfungsi sebagai alat untuk menyebarkan ajaran agama Islam. Ini dapat dilihat pada tema-tema puisi yang kebanyakan bertemakan agama dan pedoman hidup yang disampaikan dalam puisi melalui watak manusia, binatang dan sebagainya.

Antara salah satu puisi tradisional yang masih mendapat tempat serta diamalkan dalam masyarakat Melayu ialah puisi endoi. Persembahan endoi ini merupakan seni budaya Islam dalam masyarakat Melayu. Lirik-lirik puisi endoi jelas menunjukkan pengaruh Islam. Manakala corak persembahannya pula mempunyai seni yang tinggi, tersendiri dan unik, diiringi oleh kendurikendara dengan motif tertentu dan di sesetengah tempat wujudnya majlis itu seakan kemestian pula, dan sebahagiannya pula digandingkan dengan majlis perkahwinan dan hari kebesaran agama. (Ahmad Kamal Abdullah, 1988, p. 75). Puisi endoi merupakan salah satu puisi yang dikategorikan sebagai puisi tumpangan. Puisi tumpangan adalah nama yang diberikan kepada karya-karya puisi Melayu tradisional yang tidak mempunyai ciri-ciri yang khusus, melainkan menumpang bentuknya pada bentuk-bentuk puisi lain. Meskipun menumpang pada bentuk puisi lain, karya puisi ini mendokong isi atau kandungan yang berbeza dengan isi kandungan puisi yang ditumpanginya. Harun Mat Piah menjelaskan bahawa endoi bukanlah satu genre yang terasing malah dianggap sebagai syair atau variasi dalam penggunaan syair kerana endoi memiliki ciri yang ada pada sebuah syair (Harun Mat Piah, 1987, p. 71). Hal ini turut dipersetujui oleh Abdul Halim. Beliau menjelaskan puisi endoi ini menumpang bentuk syair. Meskipun karya puisi ini menumpang pada bentuk puisi lain namun isinya berbeza sama sekali (Abd Halim, 2013, p. 120). 


\section{Sejarah dan Maksud Endoi}

Berendoi adalah satu adat Melayu yang masih dikekalkan di sebahagian tempat dalam masyarakat Melayu. Berendoi juga dikenali sebagai berbuai atau adat menaiki buai. Secara ringkasnya ia dikenali sebagai istiadat menaikkan kanak-kanak ke dalam buaian yang melibatkan penyediaan buaian yang diikat dengan tali sebesar ibu jari yang berpintal daripada benang tujuh warna, kain buaian berwarna kuning diikat dengan tali dan disangkut pada kayu galang rangka buaian, kain dibuka dan dialas dengan sebidang tilam kecil pada galang buaian pula digayut bermacam-macam bunga, kain berobak-ombak yang bermanik serta digantung berbagai-bagai kuih kering. Lagu yang dinyanyikan dalam adat berendoi adalah nyanyian rakyat yang pertama dan tertua iaitu amat panjang umurnya dan tidak dapat diketahui siapakah yang mengarang atau memulai lagu-lagu itu. Nyanyian ini lahir dalam kalangan rakyat biasa dalam keadaan yang bersahaja. Setiap nyanyian rakyat bertemakan kehidupan harian masyarakat zaman dahulu dan ini termasuklah pemikiran, kepercayaan serta keinginan-keinginan mereka (Nureeyan Saleh, 1999, p. 1).

Aktiviti berendoi ini masih lagi diamalkan dalam masyarakat Melayu hari ini, khususnya di negeri-negeri utara semenanjung seperti Perak, Kedah dan Perlis malah menjadi satu kelaziman dalam kalangan orang tertentu mengadakan istiadat ini (Abdul Halim Ali, 2006, p. 106). Jika diteliti pada lirik puisi endoi setiap tempat masing-masing mempunyai perbezaan. Namun masih terdapat persamaan pada permulaan lirik, iaitu memuji Nabi Muhammad dan menceritakan tentang bagaimana bayi mula diciptakan sejak dalam kandungan ibunya hingga dilahirkan (Rosli Saludin, 2007, p. 170).

Endoi yang dinyanyikan bermula dengan memuji-muji kebesaran Allah dan diceritakan asal mula jadi kanak-kanak tersebut dari awalnya. Sehinggalah ibu tersebut mengandung dan diceritakan kesusahan ketika menjaga kandungan tersebut. Kasih semakin mendalam setelah kandungan selamat dilahirkan.

\section{Fungsi Endoi Dalam Kalangan Masyarakat Melayu}

Nyanyian ini jika diteliti dengan mendalam dapat mencerminkan kehidupan awal masyarakat Melayu sebenarnya dengan begitu baik sekali. Sebenarnya puisi endoi ini salah satu sastera lisan yang diperdengarkan kepada bayi sejak dilahirkan. Bayi serta kanak-kanak akan terhibur dengan lagu ini kerana susunan seni kata yang indah, gaya ritma dan nada yang merdu. Justeru itu lagulagu ini didendangkan oleh si ibu kepada anaknya secara nyanyian lisan yang seni katanya dihafal kerana kebanyakannya mereka tidak pandai menulis dan membaca (Nureeyan Saleh, 1999, p. 23). Namun pada hari ini, kita dapat lihat terdapat beberapa kumpulan yang ditubuhkan khas di setiap kampung untuk menjalankan aktiviti berendoi ini dan setiap kumpulan itu mempunyai liriklirik endoi tersendiri dan berbeza sama sekali dengan kumpulan yang lain. Walau bagaimanapun, matlamatnya tetap sama. 


\section{i. Menyatakan Kegembiraan dengan Kehadiran Ahli Baru}

Fungsi utama yang dapat dilihat melalui adat berendoi dalam masyarakat Melayu adalah untuk menyampaikan kegembiraan sesebuah keluarga yang menyambut kedatangan ahli baru dalam keluarga mereka. Walaupun adat ini bukan merupakan sesuatu yang diwajibkan, namun merupakan salah satu adat yang langsung tidak bercanggah dengan agama Islam itu sendiri. Kegembiraan itu amat dirasakan oleh seseorang apabila mengetahui tanda-tanda kehamilan atau menanti saat kelahiran si comel. Pada saat inilah masyarakat menunjukkan bibit-bibit kemesraan dan kecintaan terhadap kehadiran ahli baru kerana akan bertambahlah umat islam di muka bumi ini. Terdapat banyak ayat al- Quran yang menerangkan kegembiraan seseorang muslim apabila mengetahui berita tentang kelahiran anak. Antara hikmah disebalik berita baik ini akan dapat mengeratkan lagi kasih sayang dan tanggung jawab sesama muslim Abdullah Nasih Ulwan, 1991, p. 90). Kehadiran anak dalam sesebuah keluarga merupakan hadiah teristimewa. Kehadirannya dapat menggembirakan pasangan suami atau ahli keluarga serta umat Islam seluruhnya. Sebagai mukmin yang sejati tentunya mengharapkan kebaikan kepada saudara seagamanya. Sikap sedemikian dapat menanamkan kesedaran dan perasaan tanggung jawab sesama mukmin. Gembira dan sedih bersama-sama umpama satu tubuh. Apabila satu anggota berasa sakit, seluruh anggota lain turut merasakan ketidakselesaan dan kesakitannya. Firman Allah yang bermaksud:

Wahai Zakaria! Sesungguhnya kami memberi khabar yang menggembirakanmu dengan mengurniakan seorang anak lelaki bernama Yahya.

\section{(Surah Maryam, 19, p. 7)}

Di samping itu juga, kita juga digalakkan mengucapkan tahniah kepada keluarga tersebut atas kelahiran bayi mereka. Walaupun tiada hadis Rasulullah yang menyebutkan ucapan tahniah kepada mereka, namun terdapat beberapa athar para tabiin yang menyatakan hal tersebut. Antaranya:

Seorang lelaki bertanya kepadanya, "bagaimana aku hendak mengucapkan tahniah? Dia menjawab "ucapkan lah semoga Allah menjadikan anak itu membawa keberkatan kepadamu, ahli keluargamu dan umat nabi, Muhammad SAW seluruhnya".

\section{(Riwayat At-Tarmizi)}

Pendapat Athar Tabiin ini amat bermakna pada diri kita dalam mengamalkan "ucapan tahniah" yang mulia ini. Terdapat dalam sesetengah masyarakat Islam hari ini iaitu mereka lebih gemar melafazkan suatu ucapan yang tidak bersesuaian dengan sunah nabi Muhammad SAW dan amalan para tabiin. Kesimpulannya ucapan tahniah diharuskan oleh syarak dan amalan yang mulia ini perlu diteruskan jika dan tidak memudaratkan (Ibrahim Amini, 2006, p. 67). M. Ghazali (1961, p. 199) turut menyatakan kegembiraannya menyambut anak yang baru lahir ke dunia. Tetamu yang masih suci itu disambut dengan keinsafan terhadap keagungan tuhan. 
Mata yang jernih mengarah dikelahiran bayi

Selembut cahaya bulan bersinar dipagi hari

Lagu ini suling hitam bambu di hutan

Yang memuja menara tinggi keagungan tuhan

Bagi kami menghanyutkan isi dada yang kotor

Inilah harapan di dalam hati tiadakan lebur

Usman Awang (1961, p. 70) waktu menyambut kelahiran anaknya tidak lupa menghadapkan keriangannya kepada Tuhan:

Meski tidak ku tanya

Bonda mengetahui juga

Sebab antara kami pandangan mata mengisi bicara

Bergetar bibirnya: Adik Haslina seorang Putra

(tuhan, segala puji bagimu cuma!)

Bagi Shamsudin Jaafar (1989, p. 127) dalam keharuan menyambut kelahiran puteranya beliau memanjatkan doa untuk anaknya.

Tangis pertama menggema

Antara desir daun-daun

Dan kedinginann pagi

Shamsul Akmar

Ini ayah dan ibumu

Mengiringi restu dan doa pada setiap detik nafasmu.

Selain mengungkapkan kegembiraan melalui perbuatan, penyair-penyair ini juga meluahkan rasa kesyukuran itu melalui bait-bait syair dan sajak untuk menyatakan maksud mereka. Jelas di sini bahawa adat berendoi dalam kalangan masyarakat Melayu masih relevan dan patut dikekalkan. 
Jika ditanya kepada orang miskin tentang makna bahagia, mereka akan menjawab, bahagianya jika kita kaya, jika ditanya pada orang sakit, mereka akan menjawab pula bahagianya jika aku sihat. Jika ditanya kepada orang bujang, mereka akan menjawab bahagianya jika memiliki isteri solehah. Begitu julah keadaannya apabila ditanya makna bahagia bagi pasangan suami isteri, mereka menjawab, bahagianya jika mendapat anak.

(Mohd Hariri Mohd Daud, 2015, p. vii)

Sebagai agama yang menitik beratkan nilai-nilai murni dalam kehidupan seharian, ucapan tahniah di atas kelahiran anak dalam sesebuah keluarga amat dituntut kerana ianya juga merupakan tanda-tanda bagi mereka yang bersyukur di atas kurniaan dan nikmat daripada Allah SWT. Selain dapat mengeratkan hubungan antara sesama mukmin. Sesungguhnya galakan bergembira dan memberi ucapan tahniah kepada keluarga yang menerima kehadiran ahli baru dalam keluarga adalah sunat bagi seseorang Muslim.

\section{ii. Sebagai Medium Pendidikan}

Jika dilihat melalui fungsi endoi itu sendiri yang bertujuan untuk menyatakan kesyukuran dan kegembiraan dengan kehadiran ahli baru, ianya juga berfungsi sebagai tersirat, iaitu mendidik masyarakat dengan didikan moral yang baik. (Abdul Halim Ali, 2006, p. 105). Isi kandungan dalam lirik lagu endoi dapat memberi pengajaran kepada anak-anak serta masyarakat yang mendengarnya. Hal ini disebabkan oleh unsur-unsur nasihat yang terkandung dalam lirik endoi itu mampu memberi pengajaran kepada mereka. Setiap lirik tersebut mengandungi kata-kata nasihat, menyampaikan ilmu pengetahuan seperti sejarah, agama, moral atau akhlak kepada anak yang dibuaikan sehinggalah anak itu dewasa. Lagu endoi kebanyakannya disertakan ayat suci al-Quran sebagai selingan bagi memberi pendedahan awal tentang agama kepada anak yang baru lahir.

Syair memberikan kesan yang besar pada jiwa manusia, disebabkan susunan ayat dan penggunaan kalimah yang berbeza dan berlainan dengan amalan biasa. Dengan bahasa yang cantik, mesej yang disampaikan sangat mendalam untuk membangkitkan hati pendengar kepadanya. Disebabkan peranan syair yang besar kepada jiwa manusia, islam menggunakannya sebagai satu uslub dalam dakwah terutamanya pada peringkat awal Islam dahulu.

(Abdul Aziz Mohd Zin, 2001, p. 166)

Islam turut menjelaskan betapa besarnya fungsi sesebuah syair dalam menyampaikan unsur-unsur dakwah yang hendak disampaikan. 
Lagunya yang merdu sama juga dengan irama seni suara lainnya, malah ia lebih mirip kepada bacaan Quran yang mementingkan makhraj, tajwid, tertil dan sangat elok diperdengarkan kepada anak kecil.

(Wan Hanafi Wan Min, 1995, p. 12)

Peringkat bayi adalah tapak asas bagi perkembangan optimum peringkat yang seterusnya. Ketika bayi dilahirkan mereka sudah dilengkapi dengan kebolehan menerima maklumat dan belajar melalui deria sentuhan, rasa, bau, pendengaran dan penglihatan. Maka, dapat disimpulkan juga, fungsi endoi ini merupakan terapi kepada bayi. Semasa ia dinyanyikan rata-rata bayi pada waktu itu tidur dengan nyenyak dan berada dalam keadaan tenang sahaja. Pakar psikologi kerap menekankan betapa pentingnya bayi yang baru lahir didedahkan dengan aktiviti literasi bagi membantu perkembangan intelektual pada tahap permulaan. Ia dimulakan dengan nyanyian, dendangan dan lagu-lagu. Ibu bapa dan orang dewasa boleh berinteraksi dengan bayi yang masih belum memahami makna pertuturan (Ibrahim Amini, 2006, p. 32).

Oleh sebab itu lagu endoi ini ialah lagu yang dinyanyikan oleh ibu, nenek atau bapa atau secara berkumpulan untuk menghibur, membelai dan melalaikan kanak-kanak supaya cepat terlena. Seterusnya, keluarga merupakan unit sosial terkecil dalam sesebuah masyarakat. Institusi ini berperanan penting menentukan individu bagaimana yang diwujudkan dalam masyarakat tersebut. Memandangkan peranan ini, Islam memberikan penekanan penting kepada pembentukan sesebuah keluarga. Oleh itu, keluarga mempunyai tugas penting dalam pembentukan peribadi seseorang individu. Maka dapat dijelaskan bahawa, pendidikan awal anak-anak bermula daripada keluarga, iaitu ibu dan bapa. Dalam pada masa yang sama, pengkaji yakin bahawa lirik yang terdapat dalam puisi endoi ini mampu menjadi salah satu medium pendidikan yang boleh disampaikan oleh ibu atau bapa bermula sejak bayi kerana sarat dengan elemen keagamaan dan kasih sayang ibu dan anak (Salim Ali Rasyid Al- Syubli, 1999, p. 34).

\section{iii. Cara Ibu Menyatakan Kasih Sayang}

Lirik tersebut juga merupakan nyanyian yang menyatakan rasa kasih dan sayang. Kasih sayang dan cinta adalah antara emosi yang dimiliki manusia. Perkataan 'kasih' ialah perasaan dan perasaan cinta, belas kasihan serta timbang rasa. Perkataan 'sayang' juga bermaksud cinta, kasih, suka, berasa belas dan kasihan. Perkataan 'cinta' pula bermaksud perasaan sangat kasih, sayang yang sangat mendalam Lagu-lagu tersebut dipunyai oleh ibu bapa dan dilahirkan khusus untuk pendengaran anak-anak mereka. Pernyataan kasih sayang yang amat mendalam itu disusun dalam bentuk puisi, berisi lirik yang gemalai dan dihasilkan secara spontan (Harun Jaafar, 1996, p. 39).

Kelahiran bayi dalam kalangan masyarakat Islam selalunya disambut dengan penuh keriangan dan kasih sayang. Biasanya ia disambut dengan kenduri kesyukuran di samping piji-pujian terhadap kebesaran tuhan yang menyelamatkan ibu yang bersalin dan mengalu-alukan kedatangan manusia baru disisi keluarga dan masyarakat. Mudah-mudahan anak itu akan menjadi anak yang salih dan beriman.

(Ahmad Kamal Abdullah, 1988, p. 2)

e ISSN 2735 - 1904

https://doi.org/10.22452/JOMAS.vol31no1.7 
Jelaslah bahawa antara fungsi puisi endoi itu merupakan ungkapan-ungkapan yang sangat bermakna buat anak. Masyarakat Melayu menzahirkan rasa bahagia itu melalui puisi tersebut. Jelaslah bahawa makna bahagia bersifat subjektif dan nikmat bahagia paling besar ialah masuk ke syurga Allah yang kekal abadi. Tabiat semula jadi manusia inginkan anak dan sayang kepada anak. Tabiat semulajadi ini ada dalam setiap hati manusia yang bergelar suami isteri dan perasaan itu sangat mendalam pada jiwa masing-masing. Maka tidak hairanlah jika al-Quran turut menggambarkan perasaan sayang terhadap anak sebagai perhiasan dunia. Firman Allah SWT:

"Harta benda dan anak pinak itu merupakan perhiasan hidup di dunia dan amal-amal soleh yang kekal faedahnya itu lebih baik pada sisi Tuhanmu sebagai pahala balasan, dan lebih baik sebagai asas yang memberi harapan"

(Surah Al-Kahfi, Ayat 46)

\section{iv. Sebagai Alat Kawalan Sosial}

Jika diteliti watak yang ditonjolkan dalam lirik endoi memainkan peranan besar sebagai alat kawalan sosial yang berkesan. Akhlak Nabi Muhammad dijadikan contoh dan teladan kepada pendengar khususnya bayi yang diraikan. Dalam lirik ini telah menceritakan serta menuntut pendengar supaya mencontohi akhlak Rasulullah. Di samping itu juga endoi yang yang dinyanyikan bermula dengan memuji-muji kebesaran Allah dan diceritakan asal mula kejadian anak dalam rahim seorang ibu sehinggalah diceritakan kesusahan dan kepayahan melahirkan dan memelihara anak sehinggalah dewasa. Sebelum bayi di ayunkan, dibacakan doa selamat terlebih dahulu bagi memberkati majlis tersebut. jelas dapat dilihat unsur-unsur keagamaan yang diterapkan melalui lirik endoi ini mampu membentuk peribadi anak-anak kerana kita sememangnya wajib memperkenalkan agama seawal kelahiran lagi. Islam dengan tabiatnya yang memenuhi fitrah manusia itu telah pun menentukan tanggung jawab yang penting dan besar yang harus dilaksanakan oleh ibu bapa. Jika tanggung jawab ini dilaksanakan dengan sempurna maka pastilah akan membuahkan natijah atau hasil yang baik dan cemerlang. Firman Allah SWT:

Maksudnya: "Peliharalah dirimu dan ahli keluargamu dari api neraka yang bahan bakarnya terdiri dari manusia dan batu."

(At-Tahrim:6)

Pembentukan anak-anak yang utama adalah pada waktu kecil, maka apabila seorang anak dibiarkan melakukan sesuatu yang kurang baik dan kemudian menjadi kebiasaannya maka akan sukarlah memperbetulkannya apabila mereka dewasa (Abdullah Nasih Ulwan, 1991, p. 47). Daripada lirik lagu endoi tersebut terdapat beberapa penjelasan yang boleh dijadikan sebagai pegangan. Pertama, jelas keunikan yang terpancar pada lirik-lirik lagu endoi yang mana mampu menguasai emosi kanak-kanak serta bayi yang baru lahir. Malahan masyarakat sekeliling yang mendengar nyanyian tersebut turut terkesan. Kedua, masyarakat Melayu mempunyai cara tersendiri mempamerkan rasa kasih sayang antara ibu dan anak. Hal ini dinyatakan secara terus melalui upacara adat berendoi. Ketiga, pendidikan yang pertama patut diberi kepada anak-anak 
ialah pendidikan agama. Melalui adat berendoi ini dapat mendekatkan diri kanak-kanak mengenali agama serta Nabi Muhammad yang dinyanyikan dalam upacara tersebut (Ibrahim Amini, 2006, p. 89). Walaupun telah ditelan masa, lirik lagu-lagu endoi masih tersimpan dalam ingatan mereka yang pernah mengalaminya. Ini dapat dilihat setiap kali seorang ibu yang menidurkan anaknya, secara spontan lagu-lagu endoi ini meniti dibibir mereka. Berdasarkan penjelasan-penjelasan di atas, maka masih ada harapan untuk mengelakkan kepupusan lagu-lagu endoi dalam masyarakat Melayu jika ada usaha dibuat ke arah itu.

\section{Pengertian Dakwah}

Dakwah bermaksud seruan. Dalam konteks dakwah Islamiah, seruan yang dimaksudkan ialah seruan kepada kebaikan (amar makruf nahi munkar) sebagaimana yang dinyatakan dalam ayat al-Quran surah Ali Imran ayat 104 dan ayat 110. Abdul Aziz Mohd Zin (2005) mendefinisikan dakwah sebagai suatu kegiatan ajakan baik dalam bentuk lisan, tulisan, tingkah laku dan sebagainya yang dilakukan secara sedar dan berencana dalam usaha mempengaruhi orang lain secara indiviu mahupun secara kelompok agar timbul dalam dirinya satu kesedaran, sikap penghayatan serta pengalaman terhadap ajaran agama sebagai mesej yang disampaikan kepadanya dengan tanpa adanya unsur-unsur paksaan. Mmenurut Wan Hussein Azmi (1984, p. 2) pula, beliau memetik pandangan Sheikh Ali Mahfuz yang menyatakan bahawa dakwah adalah merangsang manusia kepada Allah SWT dan melakukan kebaikan supaya mereka selamat di dunia dan akhirat. Dakwah yang ditujukan kepada masyarakat Islam merupakan seruan ke arah penghayatan ajaran dan nilai Islam. Manakala dakwah yang ditujukan kepada masyarakat bukan Islam pula merupakan ajakan dan seruan kearah beriman kepada Allah SWT dengan menerima segala ajaran dan nilai Islam.

Antara perkara utama yang perlu diberi perhatian oleh umat Islam dalam kehidupan mereka ialah isu dakwah. Ini kerana dakwah merupakan salah satu daripada kewajipan di dalam agama Islam yang tidak boleh diabaikan oleh setiap Muslim. Ada tanggapan bahawa dakwah hanya perlu dimainkan oleh segolongan tertentu sahaja daripada umat Islam mereka meletakkan kewajipan dakwah ini kepada agamawan sahaja. Ulama, guru-guru agama, pegawai agama dan mereka yang terlibat dalam bidang agama sahaja yang dilihat sebagai berperanan dalam bidang ini. Selain golongan itu terlepas daripada kewajipan ini. Sedangkan Islam telah mengangkat dakwah itu ke satu mercu yang amat tinggi yang perlu digapai oleh setiap Muslim yang peka terhadap permasalahan umat lalu dijanjikan dengan balasan yang sangat tinggi bagi mereka yang terlibat dengannya. Inilah juga tugas hakiki bagi setiap rasul yang diutus oleh Allah SWT di muka bumi ini dengan membawa ajaran Islam agar dipraktikkan dan dijadikan sebagai suatu cara hidup pada semua peringkat kehidupan sama ada bagi individu, masyarakat, negara, malah seluruh alam ini sesuai dengan sifat Islam itu sendiri yang menjadi rahmat kepada seluruh alam (Muhamad Yusoff Khalid, 2002, p. 122). Oleh kerana dakwah ini terlalu penting dalam agama Islam, maka setiap penganut Islam mestilah peka dengan perkara ini dan memastikan risalah Islam terus tersebar di muka bumi ini. Sesungguhnya setiap Muslim itu sama ada lelaki atau perempuan yang mencapai akhil baligh wajib untuk berdakwah mengikut kemampuan dan keupayaan masing-masing. Hal ini sebagaimana yang disabdakan oleh Rasulullah SAW: "Sampaikanlah daripadaku walaupun satu ayat".

e ISSN 2735 - 1904

https://doi.org/10.22452/JOMAS.vol31no1.7 


\section{Pengertian Dakwah Bil Lisan}

Dakwah lazim berkembang pada ketika ini ialah Dakwah Bil Lisan/ Bil Qoul, Dakwah Bil Qalam/ Bil Kitabah dan Dakwah Bil Hal. Daripada kaedah-kaedah tersebut, makalah menggunakan kaedah Dakwah Bil Lisan sebagai kaedah dalam menyampaikan dakwah melalui puisi endoi. Dari segi bahasa Dakwah bererti panggilan, seruan, atau ajakan. Manakala secara istilah dakwah sebagai kegiatan untuk mengajak manusia untuk mengerjakan kebaikan dan mengikuti petunjuk, menyuruh mereka dari perbuatan yang tidak baik agar mereka mendapat kebahagian dunia dan akhirat. Perkataan lisan dapat diertikan sebagai bahasa atau perkataan. Dakwah ini disampaikan dalam bentuk ceramah, pengajian, khutbah atau penyampaian dan ajakan kebenaran dengan katakata. Jadi Dakwah Bil Lisan ini sangat sesuai diaplikasikan pada puisi kerana lirik puisi tersebut disampaikan secara lisan kepada pendengar (Abdul Karim Zaydan, 2002, p. 156).

Secara kesimpulannya Dakwah Bil Lisan dapat diertikan sebagai penyampaian pesan melalui perkataan. Istilah lain bagi mesej yang disampaikan secara lisan ialah komunikasi verbal seperti ceramah atau komunikasi antara da'i dan mad'u. Dakwah Bil Lisan ini sering digunakan dalam masyarakat dahulu kerana kerana tahap awal kebudayaan manusia kegiatan membaca dan menulis belum ada. Maka dakwah dilakukan dengan metode Dakwah Bil Lisan. Mereka mengajarkan dan menjelaskan pada masyarakat tentang prinsip-prinsip kebenaran. Lalu hal-hal yang telah diajarkan tersebut diamalkan dan disampaikan pula pada generasi-generasi berikutnya sebagai tradisi (Abdul Karim Zaydan, 2002, p. 187). Puisi dicipta dengan tulisan serta dikomunikasikan. Beliau turut berpendapat bahawa puisi melalui tulisan menusuk dalam diri seseorang secara personal, lebih khusus dan lebih mendalam. Puisi melalui lisan berlangsung dalam alam komunikasi yang lebih bersifat kolektif. Sesetengah golongan sasaran lebih suka mendengar berbanding dengan membaca. Maka melalui lisanlah seseorang dapat menyampaikan sesuatu yang baik kepada golongan sasaran. Daripada huraian di atas, jelaslah bahawa puisi dapat dijadikan sebagai media dakwah, kerana melalui kata-kata yang terangkai dalam bait-bait puisi, pesan-pesan dakwah dapat disampaikan kepada masyarakat atau pembaca (Abdul Aziz, 2001, p. 245).

\section{Citra Dakwah Dalam Lirik Puisi Endoi}

Dalam majlis berendoi, sebanyak dua buah lirik puisi yang akan diperdendangkan kepada khalayak. Lirik yang pertama merupakan lirik pembukaan. Lirik pembukaan ini khusus menceritakan tentang perihal Nabi Muhammad. Lirik yang kedua pula menjurus kepada harapan dan unsur-unsur nasihat daripada ibu bapa terhadap anak yang dibuaikan. Antara keunikan yang disampaikan dalam lirik puisi endoi yang pertama ialah menceritakan salasilah dan riwayat hidup Rasululllah, puji-pujian terhadap Nabi serta susur galur kehidupan Baginda menjadi tirai pembukaan puisi tersebut. Di samping itu, mesej yang terkandung di sebalik keseluruhan kisah junjungan besar Rasulullah SAW itu mencakupi bidang dakwah, menyeru masyarakat ke arah kebaikan dengan menghuraikan contoh langsung pekerti mulia baginda yang merangkumi semua aspek kehidupannya. Berikut merupakan lirik pertama yang didendangkan atau lebih dikenali sebagai lirik pembukaan dalam puisi endoi selepas bacaan selawat nabi. 
Bismillah itu nama yang mulia

Disebutkan Rasul enaknya nama

Nyanyi Fatimah nazar penama

Dengan saudara wahai semuanya

Ya Illahi Ya junjungan

Datanglah Jibrail membawa firman

Nabi Muhammad akhirlah zaman

Menyuruhnya umat membawa iman

Banyaklah hari antara hari

Tak ada semulia hari jumaat

Banyaklah Nabi antara Nabi

Tak ada semulia Nabi Muhammad

Nabi Muhammad utusan yang utama

Disebutkan Rasul empunya nama

Dendang Fatimah nazam bernama

Marilah kita berdendang bersama

Dua puluh lima Rasul pilihan

Nama yang disebut di dalam Al-Quran

Martabatnya tinggi dilebihkan tuhan

Hendaklah ingat kita sekalian

Mula pertama Nabi Allah Adam

Nenek manusia kafir dan Islam

Asal kejadian di Darul Salam

Ditempa Jibrail tanah segenggam

Adam dijadikan seorang diri

Berjalan di syurga sehari-hari

Dilihatnya burung dua sejoli

Inginlah Adam hendak beristeri 
Cintanya Adam Allah ketahui

Dijadikan Hawa dirusuk kiri

Allah mengahwinkan Jibrail

Diberi hantaran selawatkan nabi

Dikahwinkan Allah di dalam syurga

Suami isteri bersuka-suka

Datanglah iblis berbuat cela

Jadilah Adam mendapat duka

Yang kedua puluh lima sehinggalah khatam

Nabi Muhammad Sayyidul Anam

Intan mahkota junungan alam

Memberi rahmat sekalian alam

Nabi Muhammad kekasih Allah

Ibunya Aminah ayahnya Abdullah

Dinegeri Mekah zahirnya sudah

Menyampaikan pesuruh serta amanah

Teranglah bulan cahaya nurani

Siti Aminah beranakkan nabi

Nabi jadi malam isnin

Rabiul Awal bernamanya bulan

Masjid Mekah dilingkung gunung

Kaabah Allah ditengah-tengah

Wali Allah duduk termenung

Hatinya gundah kepada Allah 
Hajarul Aswad dikanan pintu

Hitamnya bukan lagi suatu

Pnuh sesak orang disitu

Kecil dan besar tiada tertentu

Dari Mekah ke Madinah

Singgah bermalam di tepi laut

Tunduk menangis Siti Aminah

Terkenangkan zaman nabi Allah Daud

Masjid Madinah menaranya tujuh

Tempat--menanti subuh

Sudahlah ia duduk bertimpuh

Khalifah pun turun lalu telimpuh

Di negeri Madinah di tengah padang

Masjidnya berkota-kota batu

Kiri dan kanan mata memandang

Hati berharap kepada Allah tuhan yang satu

Qul huwallah mula di surat

Sudah disurat lalu digulung

Nabi Muhammad turun berangkat

27 Ramadhan malaikat memayung

Lirik puisi Endoi ini merupakan kepunyaan sebuah kumpulan yang aktif berendoi dan terkenal di negeri Kedah. Ketua kumpulan tersebut menyatakan tidak dapat diketahui penulis sebenar kerana lirik ini ditulis oleh individu berdasarkan nyanyian lisan yang diperturunkan oleh nenek moyang suatu ketika dahulu. Lirik di atas merupakan lirik pembukaan puisi endoi. Berdasarkan lirik diatas, melalui penyampaian secara lisan, para pendengar dapat mengingati semula sejarah keturunan Nabi Muhammad SAW serta susur galur keturunan Baginda. Hal ini juga merupakan 
medium pendidikan kepada para pendengar sama ada kanak-kanak atau pun orang dewasa. Lirik tersebut menceritakan keagungan Nabi Muhammad yang dilahirkan pada 12 Rabiulawal. Pada setiap kali mengingati kelahiran Baginda, di masjid atau surau akan diadakan kenduri, bacaan alQuran dan selawat Nabi. Rasullullah membawa berita gembira dan memberi petunjuk yang benar kepada umatnya. Kemuliaan sifatnya sebagai Rasul melengkapkan segala-galanya serta keelokan pekerti Baginda sudah sepatutnya dijadikan contoh teladan dalam menjalani kehidupan seharian.

Unsur dakwah yang terkandung ini diutarakan kepada khalayak untuk menanamkan nilainilai murni dalam kalangan umat Islam. Selain menceritakan tentang keagungan Nabi tercinta iaitu Nabi Muhammad, lirik tersebut juga jika dilihat pada rangkap yang ketiga belas menceritakan asal usul keturunan manusia yang berasal daripada Nabi Allah Adam. Hal yang turut menjadi pengajaran kepada para pendengar adalah lirik tersebut menyentuh tentang kejadian manusia yang berasal daripada tanah.

Demikianlah puji-pujian yang ditujukan kepada Nabi Muhammad SAW berasaskan contohcontoh lirik puisi tersebut. Kewujudannya menunjukkan rasa cinta dan kasihnya umat Islam terhadap Rasulullah. Berselawat ke atas nabi juga adalah sangat-sangat dituntut dalam agama (Abdul Halim El-Muhammady, 1992, p. 98).

Berikut merupakan lirik puisi endoi yang kedua:

Lailahaillah Muhammad pesuruh Allah

Dengan Bismillah kami mulai

Alhamdulillah wassolatul nabi

Dengan takdir Ilahi Rabbi

Sampai maksud yang dicintai

Seorang anak cinta yang lama

Sekarang kami sudah terima

Seorang anak diberi nama

Kami ayunkan bersama-sama

Emas dan perak kami ayunkan

Anak ditaruh di dalam ayunan

Tali ayunan kami pegangkan

Emas dan perak kami nyanyikan 
Dipanggilkan kami orang sekalian

Olehnya ibu bapa mu tuan

Serta diberi minum dan makan

Menyatakan syukur kepada tuhan

Syukur kepada Allah Taala

Kerana mendapat intan gemala

Memberi sedekah berapa pula

Dengan sekadarnya ada segala

Dipanggil sekalian kaum kerabat

Serta sekalian handai sahabat

Segala jiran kaum berdekat

Semuanya datang dengan selamat

Jauh dan dekat datang sekalian

Besar dan kecil laki-laki dan perempuan

Sesetengahnya datang berbasikal dan berjalan

Sesetengah berjalan berpayung awan

Inilah kami datang bertalu

Menjunjung engkau hilir dan hulu

Menyata engkau maksudlah begitu

kerana hajat ibu bapa mu

Jika panjang sudah umur mu

Jasa mereka balas oleh mu

Wahai anakku fakir olehmu

Besar hati ibu bapa mu

Ibu bapamu mari dengarkan

Anak di ayun kami nyanyikan 
Bersama-sama kita doakan

Harap Allah minta perkenankan

Wahai anakku di dalam ayunan

Kami berpesan engkau ingtkan

Di atas kepala engkau junjungkan

Di dalam hati engkau taruhkan

Laila haillallah

Hidup dan mati perintah Allah

Berekatlah syafaat ya Rasulullah

Tetapkan iman rezeki murah

Kamilah mengayun terlalu banyak

Pantun dan syair bertambah banyak

Kamilah berpesan masukkan ke otak

Di bawa berjalan janganlah campak

Wahai anakku muda jauhari

Pesan kami engkau ingati

Engkau masukkan ke dalam hati

Jangah ditaruh di ibu kaki

Wahai anakku muda cemerlang

Engkau doakan malam dan siang

Sembahyang itu jangan dibuang

Dosanya besar bukan kepalang

Allah ya Allah Malikul Fitrah

Budak ini besarnya tuah

Siang dan malam makin bertambah

Sehingga sampai ia berpindah 
Awal Bismillah mula disurat

Sidah disurat digulung-gulung

Nabi Muhammad turun berangkat

Malaikat yang banyak mengembang payung

Wahai anakku kami ayunkan

Engkaulah ini kami doakan

Umur pendek minta panjangkan

Rezeki yang halal minta mudahkan

Dari Mekah ke Madinah

Singgah bermalam di tepi laut

Tunduklah menangis siti Fatimah

Mendengarlah suara Nabi Allah Daud

Allah ya Allah Malikul Rabbi

Limpah dan makmur sehari-hari

Sujudkan badan terangkan hati

Budak ini murahkan rezeki

Tuan haji berbaju jubah

Turun ke padang memburu rusa

Tuan mengaji memuji Allah

Tuan sembahyang mengampun dosa

Allah ya Allah Malikul Jabbar

Budak ini yang telah besar

Jauhkan daripada neraka yang mungkar

Dunia akhirat supaya terbesar

Banyak bulan bilangan bulan

Manakan sama bulan puasa

Banyak tuhan bilangan tuhan

Manakan sama tuhan yang Esa 
Allah ya Allah Malikul Izzati

Budak ini tetapkan hati

Minta kurniakan pangkat yang tinggi

Di akhirat boleh engkau terpuji

Banyak hari bilangan hari

Manakan sama hari jumaat

Banyak nabi bilangan nabi

Manakan sama nabi Muhammad

Allah ya Allah Malikul Rahman

Budak ini tetapkan iman

Amal ibadat minta kuatkan

Syaitan iblis minta jauhkan

Kalau ada jarum yang patah

Jangan disimpan di dalam peti

Kalau ada silap dan salah

Jangan disimpan di dalam hati

Allah ya Allah Malikul Mannan

Doa kami minta perkenankan

Siang dan malam sepanjang zaman

Bala dan fitnah minta jauhkan

Sayanglah terkukur dimasak lemak

Tanamlah selaseh dibalik batang

Dalam lumpur lagikan semak

Kerana kasih kami datang 
Tamatlah tuan anak sambil diayun

Sanak saudara kami mengayunkan

Serta meminta kami doakan

Supaya terang anak budiman

Tanamlah keduduk di balik rumah

Akar melilit ditiang seri

Kami nak duduk tuan punya rumah

Kami nak balik meminta diri

Telah selesai kami nyanyikan

Kami meminta serta selamatkan

Kami membuai jangan dimudahkan

Seumur hidup anak ingatkan

Budak-budak baik mengaji

Kalau alim biar terpuji

Cukup rukun naik kehaji

Supaya ziarah makam nabi

Allah ya Allah tuhan kami

Nabi Muhammad penghulu kami

kitab Al-Quran ikutan kami

Baitullah kiblat kami

Keseluruhan lirik puisi endoi yang kedua ini menunjukkan lirik ini mempunyai hubungan rapat antara ibu, bapa dan anak. Lirik ini, menunjukkan unsur-unsur kasih sayang ibu dan ayah terhadap anak yang dilahirkan. Kelembutan dan kehalusan menjadi titik tolak dalam amalan hidup masyarakat Melayu yang terkenal dengan sopan santun. Pernyataan kasih sayang yang amat mendalam itu disusun dalam bentuk puisi. Keadaan ini telah menampakkan keistimewaan dan kebolehan orang-orang Melayu menyesuaikan dan meletakkan sesuatu pada tempatnya (Abu Fathan, 1996, p. 23). 
Jika diperhatikan pada setiap rangkap lirik tersebut kita akan dapati betapa besarnya harapan ibu dan ayah mendoakan anak mereka supaya terhindar daripada bala bencana, fitnah dan segala unsur-unsur yang tidak baik. Apa yang diharapkan pada anak ialah supaya dipanjangkan umur, menjadi manusia yang taat perintah Allah, menjadi kebanggaan agama, bangsa dan negara. Begitulah gambaran betapa kasihnya ibu dan ayah serta betapa besarnya harapan mereka.

Setiap manusia itu secara semula jadinya memerlukan kepada teman untuk dia menyayangi dan disayangi. Suami memerlukan seorang isteri, isteri memerlukan seorang suami, rakan memerlukan rakan dan begitulah selanjutnya. Tetapi sebenarnya kehadiran mereka yang dimaksudkan itu masih belum cukup untuk menggembirakan hati melainkan dengan kehadiran seorang anak sebagai pelengkap segala kekurangan (Abdullah Nasih Ulwan, 1991, p. 75). Sesungguhnya kasih sayang seorang kawan adalah suatu kebahagiaan yang unggul bagi manusia di dunia ini. Begitu juga dengan kasih sayang ibu, isteri atau suami. Akan tetapi kasih terhadap anak adalah kemuncak segala keunggulan itu tadi. Pelbagai cara ditunjukkan oleh seorang ibu untuk menyatakan perasaan kasihnya terhadap anak yang dilahirkan.

Maksud sebenar dengan perkataan perasaan ialah menimbulkan apa yang diletakkan oleh Allah dalam hati ibu daripada kasih sayang dan belas kasihan serta rahmat terhadap anak-anak mereka. Perasaan itu begitu mendalam pada jiwa masing-masing. Kasih sayang dan cinta adalah di antara emosi yang dimiliki manusia. Itulah yang ditanam sejak seseorang itu bakal menjadi seorang ibu. Tabiat semula jadi ini ada dalam setiap hati manusia yang bergelar seorang ibu. Perasaan itu sangat mendalam pada jiwa masing-masing. Maka tidak hairanlah jika al-Quran turut menggambarkan perasaan sayang terhadap anak sebagai perhiasan dunia. Allah SWT berfirman dalam al-Quran:

Harta benda dan anak pinak itu merupakan perhiasan hidup di dunia dan amal-amal soleh yang kekal faedahnya itu lebih baik pada sisi Tuhanmu sebagai pahala balasan, dan lebih baik sebagai asas yang memberi harapan.

(Surah Al-Kahfi: 46)

Selain itu juga dalam lirik yang kedua ini juga ada menyatakan tentang beberapa perkara ibadah wajib yang perlu dilakukan seperti mendirikan solat lima waktu. Jika kita meninggalkan solat maka akan berdosa besar. Pengajaran ini sangat berguna diperdengarkan kepada kanak-kanak dan orang dewasa supaya mereka sentiasa beringat dan tidak meninggalkan salah satu rukun Islam, iaitu mendirikan solat. Selain itu juga, lirik puisi ini juga ada menekan kan tentang rukun haji yang perlu dilaksanakan sekiranya berkemampuan (Abu Fathan, 1996, p. 68).

Perbincangan di atas menunjukkan bahawa objektif utama dalam upacara berendoi ini ialah untuk mendidik seluruh anggota masyarakat supaya mengamalkan semua bentuk nilai murni yang dianjurkan oleh agama Islam. Harus diingat bahawa bayi yang diendoikan sebenarnya belum mengerti apa-apa maksud. Namun ini merupakan aktiviti yang mempunyai objektif yang tersembunyi, iaitu mendidik atau mentarbiah orang yang mendengarnya iaitu golongan kanakkanak, remaja dan dewasa. Pendidikan seumur hidup dan nasihat-menasihati secara lembut dipraktikkan dalam upacara ini. Lagipun sudah menjadi adat dan budaya masyarakat Melayu itu 
sendiri menyampaikan sesuatu dengan cara yang penuh berhikmah sepeti peribahasa, "menarik rambut dalam tepung, tepung jangan berselerak, rambut jangan putus". Maka dengan itu hadirinlah yang cuba dididik oleh puisi endoi tidak kira sama ada mereka itu orang dewasa atau kanakkanak yang sudah dapat memahami sesuatu. Bayi yang diendoikan itu hanya sekadar untuk diperdengarkan ungkapan-ungkapan yang baik dalam puisi tersebut.

\section{Kesimpulan}

Setelah ditinjau dari sudut isi kandungan dalam beberapa contoh lirik puisi endoi di atas, keseluruhan isi kandungan tersebut terdiri daripada unsur-unsur keagamaan dan pendidikan. Dakwah Islamiah menjadi tema yang mendasari puisi tradisonal ini. Lirik yang disampaikan dalam puisi ini sangat bertepatan dengan konsep Dakwah Bil Lisan, iaitu unsur-unsur pengajaran disampaikan melalui perkataan, pertuturan seperti dalam salah satu kesenian Melayu ini. Cara penyampaian melalui kesenian dan hiburan dalam Islam ini, mampu menjadikan pendengarnya insan yang bertakwa. Kecenderungan ini meresap ke dalam puisi-puisi berkenaan bila disusur galurkan hubungan antara ke duanya. Puisi melagukan tentang kehidupan. Pada masa yang sama turut memperkayakan pengalaman dan menghaluskan perasaan manusia (Wahyunah Hj. Abdul Ghani, 2000, p. 56). Jika diteliti, isi kandungan puisi endoi ini merangkumi tiga aspek penting dalam kehidupan manusia, iaitu ketuhanan, kerasulan dan kemanusiaan dan menyentuh tentang akidah, syariah dan akhlak. Oleh hal yang demikian, ajaran-ajaran Islam tidak hanya menyangkuti hubungan manusia dengan Allah, malahan juga hubungan sesama manusia. Perkara-perkara tersebut menjadi inti pati dalam puisi endoi tersebut.

Secara keseluruhannya puisi endoi membawa amanat yang selari dengan tuntutan Islam, iaitu menyeru semua manusia menurut perintah Allah dan Rasul, meninggalkan segala yang terlarang dan berbuat baik sesama manusia. Selain itu juga terkandung dalam lirik puisi tersebut ialah budaya hormat menghormati terutama kepada ibu bapa. Penelitian yang dibuat terhadap bahan-bahan sastera terutamanya puisi Melayu dari segi tema, motif, amanat dan seumpamanya telah menunjukkan bahawa tujuan-tujuan yang disebutkan tadi menjadi matlamat utama penampilannya kepada masyarakat Islam hari ini khususnya. Sesungguhnya berzikir, bertakbir dan bertahmid sangat-sangat dituntut dalam agama Islam itu sendiri sebagai satu cara mengingat dan mendekatkan diri kepada Allah Azza Wajalla. Selain itu, berselawat dan mengingati serta memuliakan Nabi juga telah dijanjikan syafaat kepada kita di alam akhirat.

\section{Rujukan}

Ab. Aziz Mohd Zin. (2005). Metodologi dakwah. Kuala Lumpur: Penerbit Universiti Malaya.

Abu Fathan. (1996). Peranan Islam dalam masyarakat Melayu. Shah Alam: Albaz Publication.

Abdullah Nasih Ulwan. (1991). Pendidikan anak-anak dalam Islam. Eunos Avenue: Pustaka Nasional. Abdul Ghafar Don \& Zaleha Mohd Ali. (2008). Dakwah dan cabaran. Shah Alam: Karisma Publication Sdn Bhd.

Abdul Halim Ali. (2006). Mendekati puisi Melayu tradisional. Tanjong Malim: Penerbitan 
Profesional Baharu.

Abdul Halim El-Muhammady. (1992). Dinamika dakwah suatu perspektif dari zaman awal Islam hingga kini. Kuala Lumpur: Budaya Ilmu Sdn. Bhd.

Abdul Karim Zaydan. (2002). Islam dan dakwah. Kuala Lumpur: Pustaka Salam.

Abdul Rahim Abd Rashid. (1993). Pendidikan nilai merentasi kurikulum. Kuala L u m p u r : Dewan Bahasa dan Pustaka.

Ahmad Kamal Abdullah. (1988). Unsur-unsur Islam dalam puisi Melayu moden. Kuala Lumpur: Dewan Bahasa dan Pustaka.

Harun Mat Piah. (1989). Puisi Melayu tradisional. Kuala Lumpur: Dewan Bahasa dan Pustaka.

Ibrahim Amini. (2006). Agar Tak Salah Mendidik. Jakarta, Indonesia: Penerbit Al-Huda.

Jabatan Kemajuan Islam Malaysia. (2007). Tafsir Pimpinan Ar-Rahman. Kuala Lumpur: D a r u 1 Fikir Malaysia

Kementerian Pendidikan Malaysia. (1994). Ensiklopedia sejarah dan kebudayaan Melayu. Kuala Lumpur: Dewan Bahasa dan Pustaka.

Maniyamin Ibrahim. (2009). Konteks sastera dan budaya Melayu. Shah Alam: Karisma Publication Sdn. Bhd.

Mohd Hariri Mohd Daud. (2015). Menyambut cahaya cara gaya Rasulullah. Kuala Lumpur: Mutiara Cemerlang Sdn. Bhd.

Mohd Rosli Saludin. (2007). Seni Berpuisi. Bukit Mertajam: Goal Intelligent Publishing Sdn. Bhd.

Muhammad Haji Salleh. (1999). Menyeberangi sejarah: Kumpulan esei pilihan. Kuala Lumpur: Dewan Bahasa dan Pustaka.

Nureeyan Saleh. (1999). Lagu Dodoi Melayu Pattani. Bangi: Universiti Kebangsaan Malaysia.

Moh. Ali Aziz, M. Ag. (2004). Ilmu dakwah. Jakarta, Indonesia: Kencana Prenada Media Group.

Salim Ali RasyidAl-Syubli.(1999). Hukum menyambut kelahiran zuriat menurut sunnah rasulullah serta perkara-perkara bid'ah tentang kelahiran. Kuala Lumpur: Jasmin Enterprise.

Wahyunah Hj. Abdul Ghani. (2000). Puisi Melayu Lama Berunsur Islam. Kuala Lumpur: Dewan Bahasa dan Pustaka.

Yahya Nuryadi. (2008). Semulia akhlak Nabi Muhammad SAW. Kuala Lumpur: Progre s sive Publishing House Sdn Bhd.

Yusof Al-Qaradhawi. (2010). Halal dan haram dalam Islam. Bangi: Darul Syakir Enterprise.

Zurinah Hassan. (2012). Puisi Melayu Tradisional. Ampang: Pekan Ilmu Publication.

e ISSN 2735 - 1904

https://doi.org/10.22452/JOMAS.vol31no1.7 